\title{
Performance Analysis and Methodology for replacing conventional lamps by optimized LED arrays for Photocatalytic Processes
}

\author{
Tecilli Tapia-Tlatelpa ${ }^{a^{*}}$, Valentina Buscio ${ }^{\mathrm{b}}$, Jose Trullc, Vicent Sala ${ }^{\mathrm{a}}$
}

\author{
${ }^{a}$ Motion Control and Industrial Applications (MCIA) Research Center, Department of Electronic Engineering, \\ Universitat Politècnica de Catalunya, Rambla Sant Nebridi, 22, 08222 Terrassa, Spain. \\ ${ }^{b}$ Institute of Textile Research and Industrial Cooperation of Terrassa (INTEXTER), Universitat Politècnica de \\ Catalunya. Colom 15, 08222, Terrassa, Spain. \\ ${ }^{c}$ Nonlinear Dynamics, Nonlinear Optics and Lasers (DONLL), Department of Physics, Universitat Politècnica de \\ Catalunya, Colom 11, 08222 Terrassa, Spain.
}

\begin{abstract}
One of the main drawbacks of heterogeneous photocatalysis is the high consumption of electrical energy generated by conventional lamps. This study proposes a methodology to find the best distribution of light emitting diodes (LEDs), i.e., the least amount of elements, and the optimum distance between them in order to substitute conventional lamps in photocatalytic processes, and a performance analysis in terms of energetic efficiency, using for this the Electric energy per order ( $\left.\mathrm{E}_{\mathrm{EO}}\right)$ Figure-of-merit and the cost results for the degradation of the textile reactive dye Orange PX-2R by means of UV/TiO 2 process, using conventional lamps and different geometrical patterns of LED arrays. The obtained experimental results show that it is possible to replace sources of high-energy consumption by UV-LED arrays adapted to the specific needs for a given photocatalytic reactor obtaining suitable oxidation results, and the rate of decolorization obtained is similar to the results obtained with conventional lamps; however the UV-LEDs require $70 \%$ less electrical energy (178 vs $628 \mathrm{kWh} / \mathrm{m}^{3} /$ order) than UV-lamps. Consequently, the use of UV-LEDs enables to degrade 3.5 times more dye with the current energy consumption of UV lamps. Finally, the proper choice for an array can generate additional energy savings.
\end{abstract}

\footnotetext{
${ }^{*}$ Corresponding author: Tel: (+34) 937398574

Email address: tecilli.tapia@upc.edu (Tecilli Tapia)
} 


\section{Keywords}

Ultraviolet Light Emitting Diode, Uniform Irradiance Models, Electric energy per order (EEO),

Heterogeneous Photocatalysis, Titanium dioxide.

\section{Introduction}

Textile industry is one of the largest consumers of water, mainly due to their finishing processes, such as dyeing, printing and subsequent washing steps. In general terms between 150 and $350 \mathrm{~L}$ of water are required to produce a kilogram of textile product (Bilińska et al., 2016). In addition, wastewater from textile industry contains different types of dyes and chemical additives, which cannot be easily degraded by conventional processes (Holkar et al., 2016; Ozturk et al., 2016). Currently, the treatments applied in order to process textile effluents are based on biological or physical-chemical processes. In general, the conventional biological treatment provides good chemical oxygen demand (COD) removal, but low efficiencies in color removal, due to the chemical stability and resistance to microbiological attack of dyes. Otherwise, the coagulation-flocculation treatment can remove color completely, but generates a sludge which requires an additional treatment to be destroyed (Ahmad and Puasa, 2007; Meerbergen et al., 2017).

In recent years, the interest for advanced oxidation processes (AOPs) has increased since they generate a high pollutant removal, minimize the use of chemical reagents and reduce the environmental impact. These processes are characterized by the generation of hydroxyl radicals $(\mathrm{OH} \cdot)$ that are able to break down the organic pollutants into smaller molecules. Among the AOPs, the heterogeneous photocatalytic processes have been studied for the degradation of different textile dyes (Buscio et al., 2015; Gümüş and Akbal, 2011; Repo et al., 2013; Riga et al., 2007; Wang and Ku, 2006). The dye degradation that takes place in a photocatalytic process can be expressed according to the following Eqs. (1) to (8) (Buscio et al., 2015):

$$
\begin{aligned}
& \mathrm{TiO}_{2}+h v(U V) \rightarrow \mathrm{TiO}_{2}\left(e_{C B}^{-}+h_{V B}^{+}\right) \\
& \mathrm{TiO}_{2}\left(h_{V B}^{+}\right)+\mathrm{H}_{2} \mathrm{O} \rightarrow \mathrm{TiO}_{2}+H^{+}+\mathrm{OH}^{\bullet} \\
& \mathrm{TiO}_{2}\left({h_{V B}}^{+}\right)+\mathrm{OH}^{-} \rightarrow \mathrm{TiO}_{2}+\mathrm{OH}^{\bullet} \\
& \mathrm{TiO}_{2}\left(e_{C B}^{-}\right)+\mathrm{O}_{2} \rightarrow \mathrm{TiO}_{2}+\mathrm{O}_{2}^{-\bullet}
\end{aligned}
$$




$$
\begin{aligned}
& \mathrm{O}_{2}^{-\bullet}+\mathrm{H}^{+} \rightarrow \mathrm{HO}_{2} \\
& \text { Dye }+\mathrm{OH}^{\bullet} \rightarrow \text { degradation products } \\
& \text { Dye }+{h_{V B}}^{+} \rightarrow \text { oxidation products } \\
& \text { Dye }+{e_{C B}}^{-} \rightarrow \text { reduction products }
\end{aligned}
$$

where $\mathrm{hvB}_{\mathrm{B}}{ }^{+}$are holes in the valence band generated when an electron $\left(\mathrm{e}^{-}\right)$is promoted from the Valence Band (VB) of the photocatalyst to the Conduction Band (CB).

This process starts when the photocatalyst (i.e. $\mathrm{TiO}_{2}$ ) absorbs photons whose energy is equal to or greater than its band gap. Previous studies have found that the efficiency of the photocatalytic treatment depends mainly on the working conditions such as the light source, catalyst type, pollutant concentration, temperature and pH (Daneshvar et al., 2007; Gaya and Abdullah, 2008; Khezrianjoo and Revanasiddappa, 2016).

The most used photocatalyst is the titanium dioxide $\left(\mathrm{TiO}_{2}\right)$. The working conditions depend on the $\mathrm{TiO}_{2}$ structure but in general, due to its energy band gap (around $3.2 \mathrm{eV}$ ) it requires a source of ultraviolet light with a wavelength typically less than $400 \mathrm{~nm}$ to be excited (Chong et al., 2010; Herrmann, 2005). Also, photocatalytic activity is directly related to the illumination characteristics (as absorbance and radiant flux) (Gaya and Abdullah, 2008; Herrmann, 1999; Ung-Medina et al., 2015).

The conventional light sources used for the activation of the photocatalysts are the UV-lamps, which either work by incandesce or by gas discharge (low or high pressure). Nevertheless, the use of these conventional lamps represents some disadvantages such as fragility, toxicity (by mercury), short lifetime, high-energy consumption, among others (Bilal et al., 2018; Jo and Tayade, 2014a; Tokode et al., 2015). Additionally, a large part of the light emitted by these lamps falls out of the effective frequency range necessary to activate the $\mathrm{TiO}_{2}$. Thus, conventional lamps are being replaced by sources with low energy consumption. In this context, the rapid development of light-emitting diodes (LEDs) over the last years have opened up new opportunities. 
However, the viability of using UV-LEDs is still under discussion as efficient sources of ultraviolet light with enough energy and with the proper frequency range to be used during the oxidation process. The use of LEDs for photocatalytic processes can represent several advantages, as a reduced cost, compact size, lightweight, lower operating temperature, long lifetime as well as its directionality in order to obtain the maximum illumination towards the catalyst.

In the last years, some authors have proposed the use of UV-LEDs in order to carry out the photocatalysis processes (Jamali et al., 2013; Jo and Tayade, 2014b; Kim et al., 2016; Matafonova and Batoev, 2018; Tapia-Tlatelpa et al., 2019). In this regard, most of the current literature focuses on the direct replacement of the conventional ultraviolet lamp by LED arrays (Ghosh et al., 2009; McCullagh et al., 2011; Shie et al., 2008), without any discussion regarding to its optimal distribution. In fact, the number of LEDs changes considerably for the different proposals. Hence, a methodology that determines the minimum number of LEDs and the geometrical distribution required to effectively replace the conventional UVlamp source is a topic of potential interest.

This article addresses this problem by considering several significant factors, such as the location and angle of position of the light source, the distance between this light and the reactor, and mainly, the generation of a uniform irradiance pattern similar to that provided by the lamp to be replaced. Mathematical models for LEDs (Chen and Wu, 2010; Su et al., 2012; Wang, 2017) were used in order to accurately calculate the necessary irradiance with the aim of photoactivate the titanium dioxide. LED arrays with specific geometries to achieve a uniform illumination for a given selected plane have been generated (Moreno and Tzonchev, 2006; Ramane and Shaligram, 2011).

Taking into account these considerations, the objectives of this research were: i) to create a methodology based on uniform irradiance models with the aim to obtain the minimum number of LEDs necessary to replace ultraviolet lamps for their use in photocatalytic processes, providing for that the equivalent photonic efficiencies (the measure of the rate of reaction divided by the incident light intensity); ii) to analyze the performance of photocatalytic treatment for different reactors (operating with lamps and with different configurations of LED arrays generated by the methodology), as well as to quantify the energy 
of the process by means of Figures-of-merit in order to demonstrate the viability of the method for the photocatalytic degradation of textile dyes.

\section{Material and Methods}

\subsection{Theory: Irradiance models}

The replacement of conventional lamps by LEDs is performed imposing the condition that the irradiance generated by both sources in a specific region of reactor should be equal, since any significant difference between the irradiance of the existing and the new source can cause an alteration in the performance of the photocatalytic process. Due to the distinct emission properties of each source in terms of radiated intensity and angular emission pattern a direct comparison of the emission of a single LED with an UV lamp is not adequate. Therefore, it is necessary to determine the optimum array configuration (i.e., geometry and number of LEDs), which must be used to obtain equivalent irradiances.

\subsubsection{Irradiance model for single LED}

LED arrays will be considered formed by individual emitters with identical properties (i.e., wavelength, radiant flux, irradiance). Due to their optical characteristics, LEDs of spherical encapsulation and without encapsulation cannot be considered Lambertian emitters, so their irradiance distributions are not directly proportional to the cosine of the angle of view. Nevertheless, it is possible to obtain a practical approximation of the irradiance distribution $E(r, \theta)$ for a LED (Chen and $\mathrm{Wu}, 2010)$, given by:

$$
E(r, \theta)=E_{0}(r) \cos ^{m}(\theta)
$$

where $E_{0}(r)$ is the irradiance $\left(\mathrm{W} / \mathrm{cm}^{2}\right), r$ is the distance $(\mathrm{cm})$ on axis and $\theta$ is the view angle $(\mathrm{deg})$.

The reported values of $m$ by different authors vary, (Chen and $\mathrm{Wu}, 2010$ ) report that $m>1$, while (Moreno and Tzonchev, 2006) report that $m>30$, which indicates large variations in the emission properties of each LED. However, at the specific view angle where the irradiance takes a value equal half to its maximum value, $\theta=\theta_{1 / 2}, \mathrm{E}(\mathrm{r}, \theta)=\mathrm{E}_{0}(\mathrm{r}) / 2, m$ for Eq. (9) can be expressed by:

$$
m=\frac{-\ln 2}{\ln \left(\cos \theta_{1 / 2}\right)}
$$


Considering a single LED placed at the position $\left(x_{0}, y_{0}\right)$ in the $z_{0}=0$ plane, the irradiance at a given point with coordinates $(x, y)$ placed in a plane at distance $z$ (see Fig. 1A for a schematic representation) is obtained by writing Eq. (9) in Cartesian coordinates $(x, y, z)$ :

$$
E(x, y, z)=\frac{z^{m} I_{L E D}}{\left[\left(x-x_{0}\right)^{2}+\left(y-y_{0}\right)^{2}+z^{2}\right]^{(m+2) / 2}}
$$

where, $E(x, y, z)$ is the irradiance distribution, $I_{L E D}$ is the intensity $(\mathrm{mW} / \mathrm{sr})$ of the LED, $z$ is the distance (cm) between the LED and the target (reactor), and $m$ is given by Eq. (10).

Since the irradiance model is based on the superposition of the emissions of each individual LED, the equation modeling distinct LED arrays will vary according to the particular distribution of the LEDs in the plane $\left(x_{0}, y_{0}, 0\right)$.

A)

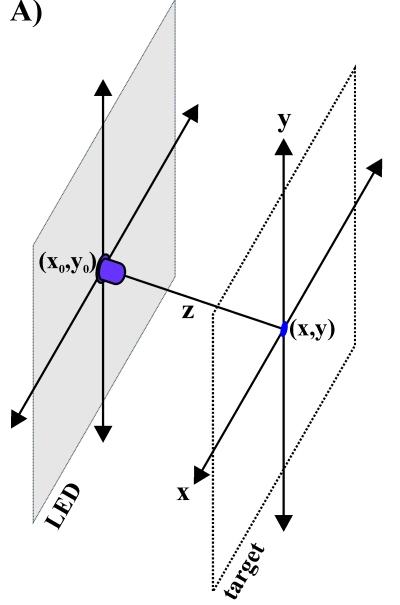

B)

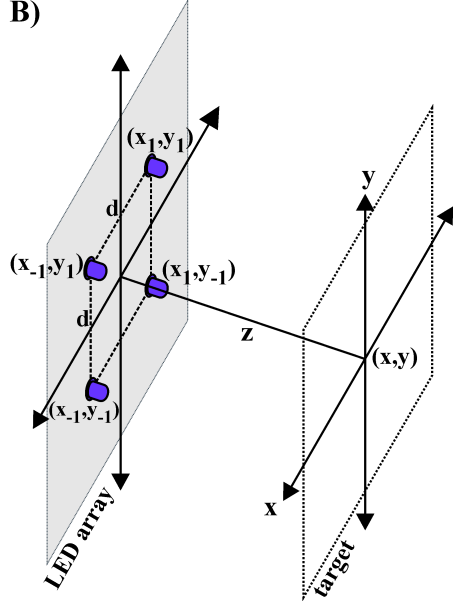

Fig. 1. Schematic representation of the LED configuration and illumination plane. A) Location of a single LED, B) Square LED array $2 \times 2$.

\subsubsection{Irradiance model for square LED array}

The most used array for lighting panels and for large lamps is the square geometry, whose irradiance $E(x, y, z)$ is the sum of the matrix consisting of MxN LEDs. As proposed by (Moreno and Tzonchev, 2006) the separation between LEDs in this configuration can be properly selected with the aim to obtain a uniform irradiance $E(x, y, z)$ for a given distance $z$ : 


$$
E(x, y, z)=\mathrm{z}^{m} I_{L E D} \times\left\{\sum_{n=1}^{N} \sum_{m_{0}=1}^{M} \frac{1}{\left[X^{2}+Y^{2}+z^{2}\right]^{(m+2) / 2}}\right\}
$$

where,

$$
\begin{aligned}
& X=x-(N+1-2 n)\left(\frac{d}{2}\right) \\
& Y=y-\left(M+1-2 m_{0}\right)\left(\frac{d}{2}\right)
\end{aligned}
$$

and $N, M$ are the number of LEDs for the $x$-axis and $y$-axis respectively.

For arrays of dimensions 2x2 (see Fig. 1B), the distance $d$ between each LED is equal for the $x$ and $y$ axis, and is given by:

$$
d=z\left(\frac{4}{m+2}\right)^{1 / 2}
$$

And for arrays with superior dimensions, distance $d$ is given by:

$$
d=z\left(\frac{1.2125}{m-3.349}\right)^{1 / 2}
$$

The requirements imposed by Eq. (16), guarantee that more than $97 \%$ of the generated irradiance of the array is found at the central region of the target.

To obtain a particular irradiance value at a given point $(x, y, z)$ (i.e., taken the plane $z$ at the reactor position) we will use Eqs. (10) to (16) imposing as initial condition the desired value of irradiance $E(x, y, z)$ at that point; the number and position of the LEDs $\left(N, M, x_{0}\right.$ and $\left.y_{0}\right)$ in the plane $z=0$ will then be changed until obtaining the final configuration that satisfies the imposed conditions. 


\subsection{Proposed algorithm}

The proposed algorithm has been developed to be adapted to the lighting requirements of reactors with different geometries, considering their dimensions and the type of LED structure that will be implemented (linear, square (Fig. 2), radial (Fig. 3), radial with central element, or hexagonal) using the minimum amount of LEDs; in addition, it is possible to specify the coordinates of the reactor zone where the maximum irradiance is desired.

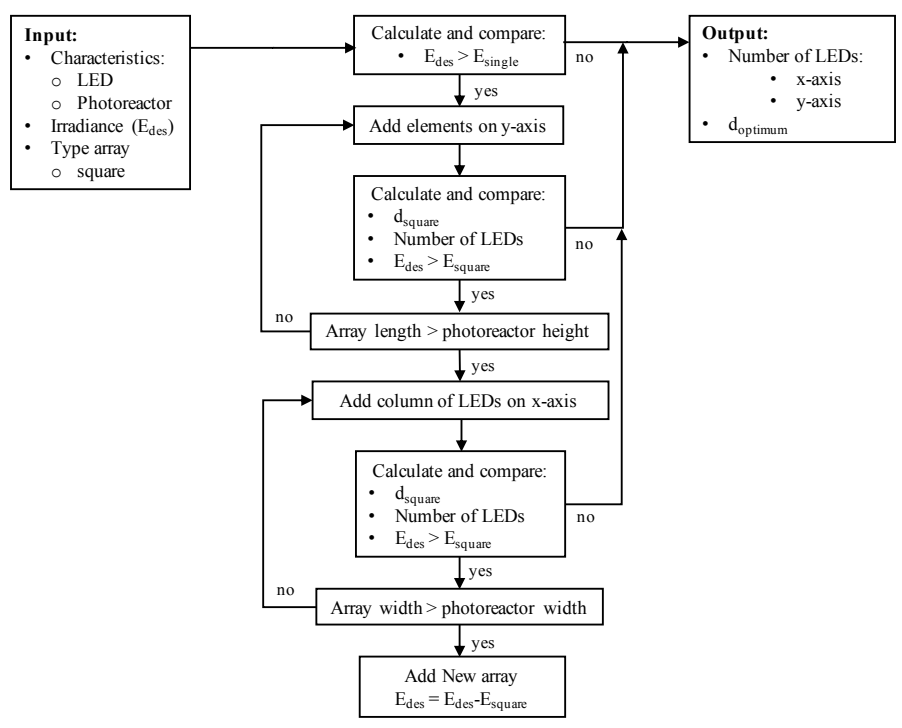

Fig. 2. Flowchart for generating square LED array.

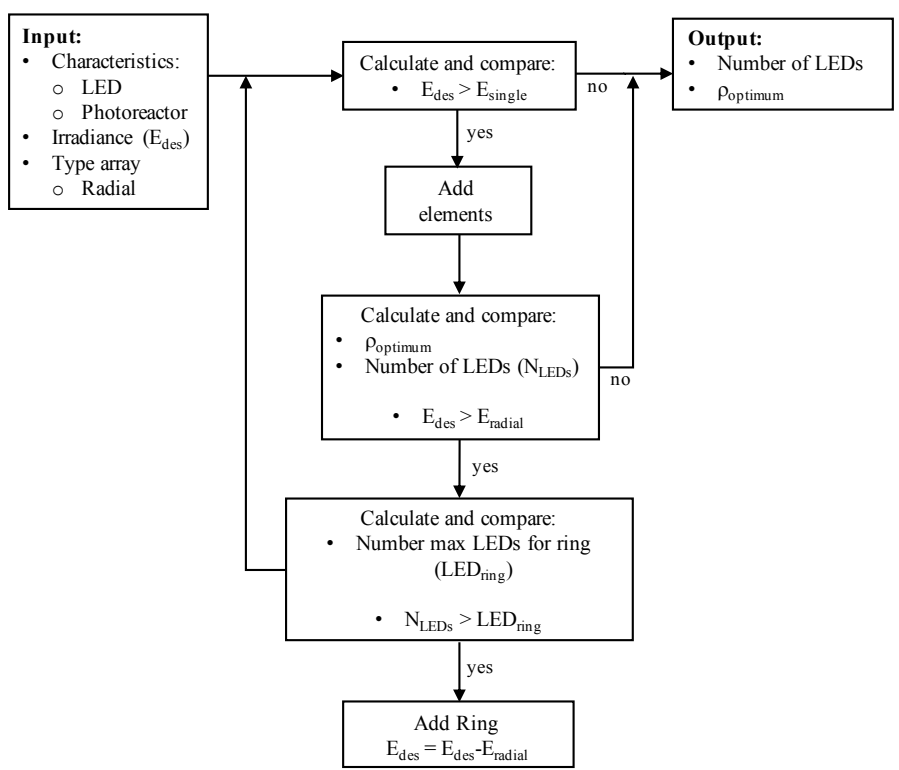

Fig. 3. Flowchart for generating radial LED array. 
In this work a cylindrical reactor illuminated from the exterior by sources placed at fixed distance from its center was used. The initial conditions were established by fixing the desired irradiance value (Edes) at the plane $z$ corresponding to the distance between the source and the center of the reactor (other options could be adopted for different reactor geometries). Additional input parameters were the data of the individual LEDs (view angle, intensity, and dimensions). Edes corresponds to the irradiance value delivered by the UV-lamp measured at the center of the reactor.

The algorithm starts by comparing the irradiance of a single LED with Edes. In the case of single LED irradiance larger than $E_{\text {des }}$ the algorithm stops. Usually this condition will be not met in the first iteration and additional LEDs should be added to form the array. Since this reactor has a defined height and it is desired to obtain a uniform illumination along the vertical direction, the next iteration in the square array algorithm is to place a second LED in this direction, separated from the first LED by a distance $d$ provided by Eq. (15).The position of the LEDs in the vertical direction is optimized to maximize irradiance and again is compared with $E_{\text {des. }}$ If the obtained value is lower than the desired irradiance, a new LED is added also in the vertical direction. The maximum number of LEDs in the vertical position is limited to the height of the reactor. If the irradiance with the maximum number of LEDs in a single column is still lower than the target value $E_{\text {des, }}$ the following iteration consists in the addition of an identical column separated from the first one by the distance given by Eq. (16) (or Eq. (15) if the array is $2 \times 2$ ), and again the position of the array is implemented in order to maximize the irradiance at the target point. The iterations continue adding new columns until the calculated irradiance is larger or equal to $E_{\text {des. }}$ Once the algorithm obtains the desired irradiance, it provides the total number of LEDs, specifying the number of elements that should be in $M$ and $N$, as well as their optimal distances.

A similar algorithm can be implemented for other array geometries. For instance, for the radial array (Fig. 3) distribution the optimum radius can be found and different number of LEDs are added on a given ring by taking in regard its optimum angular position with the aim to maximize its irradiance at the selected point. More rings can be added until the target value is obtained. This study will demonstrate the proposed method by the implementation of square and radial arrays. 


\subsection{Reagents}

The materials used for this study were: i) Orange PX-2R dye (Reactive Orange 13), with CAS number 12225-85-3, molecular weight $762.03 \mathrm{~g} / \mathrm{mol}$; ii) titanium dioxide powder $\left(\mathrm{TiO}_{2}\right)$ from the Sigma-Aldrich manufacturer (CAS number 13463-67-7), with particles of $21 \mathrm{~nm}$, surface area of $35-65 \mathrm{~m}^{2} / \mathrm{g}$ and a molecular weight $78.87 \mathrm{~g} / \mathrm{mol}$.

\subsection{Light sources}

Two types of light sources were used: i) a low pressure mercury UV-lamp, Philips PLL 18W/10/4P UVA, with peak wavelength at $360 \mathrm{~nm}$, radiated power of $3.5 \mathrm{~W}$ and power dissipation of $18 \mathrm{~W}$, operated at 370 mA. ii) UV-LEDs, Roithner LaserTechnik LED385-33 UVA, with peak wavelength at $385 \mathrm{~nm}$, radiated power of $11 \mathrm{~mW}$ and power dissipation of $200 \mathrm{~mW}$, operated at $50 \mathrm{~mA}$. With the aim to characterize the optical power of the sources, a thermopile S120VC was used. Spatial characterization of the sources was performed by measuring the optical power as a function of the angle and of the distance to the source at a constant room temperature of $22^{\circ} \mathrm{C}$.

\subsection{Photocatalytic reactors}

For the measurements of the decolorization efficiency and energy consumption from the different sources, a photocatalytic reactor was built using a $250 \mathrm{~mL}$ borosilicate vessel and a magnetic stirrer to mix the $\mathrm{TiO}_{2}$ photocatalyst. Four different configurations were tested, one using UV-lamps and three with different UV-LED array configurations (the distribution of LEDs was obtained using the algorithm explained in the section 2.2).

Fig. 4A shows the schematic photoreactor with three UV-lamps arranged at $120^{\circ}$ around the vessel, at a distance of $10 \mathrm{~cm}$ from the center of the reactor. The schematic photoreactor of Fig. 4B has three square UV-LED arrays, placed $120^{\circ}$ around the container, at a distance of $8 \mathrm{~cm}$ from the center of the reactor. Fig. 4C shows the schematic photoreactor using the UV-LED radial array, placed in the upper part of the photoreactor, at a distance of $10 \mathrm{~cm}$ with respect to the bottom of the vessel, and finally Fig. 4D is the schematic square\&radial photoreactor, combining the radial and square arrays, described above. 
The geometric configuration and the separation between UV-LEDs was selected with the aim to obtain an illumination as uniform as possible in the reactor with intensities comparable to that given by the UVlamps used in the first configuration (Fig. 4A).

A)

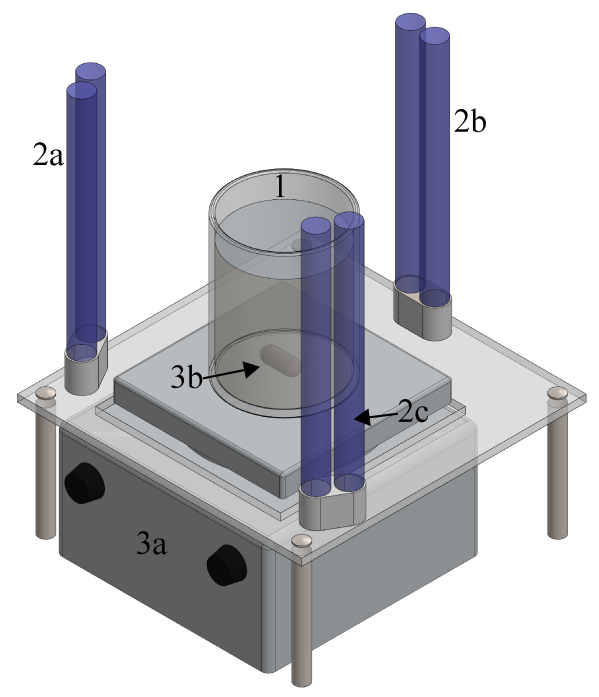

C)

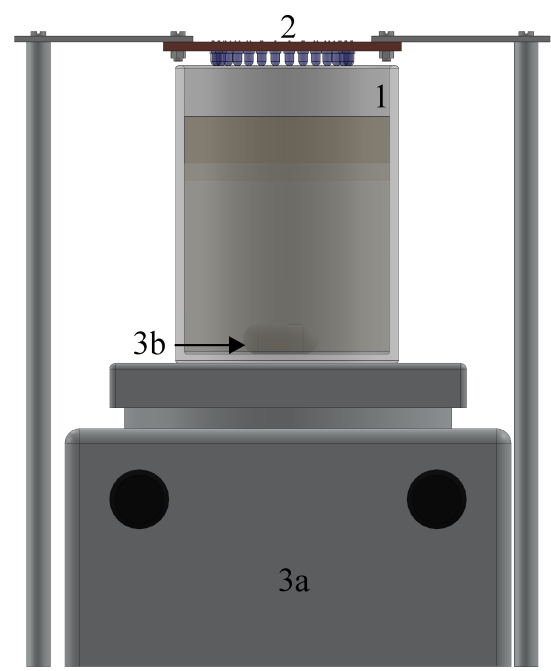

B)

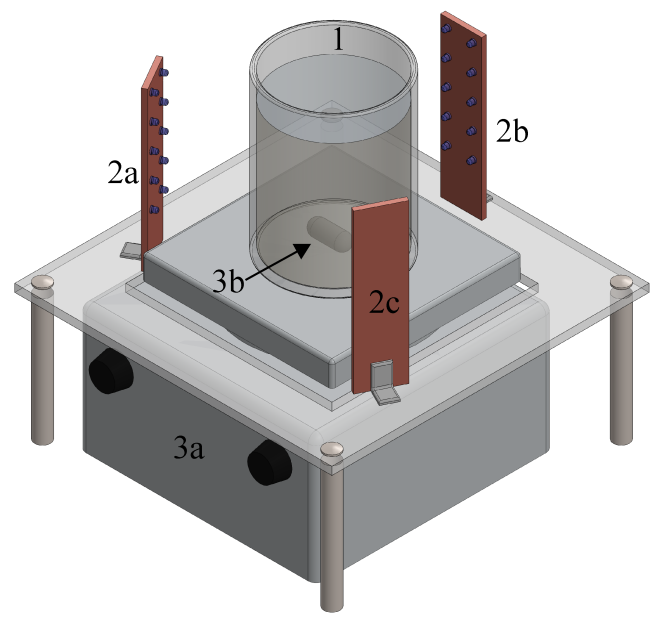

D)

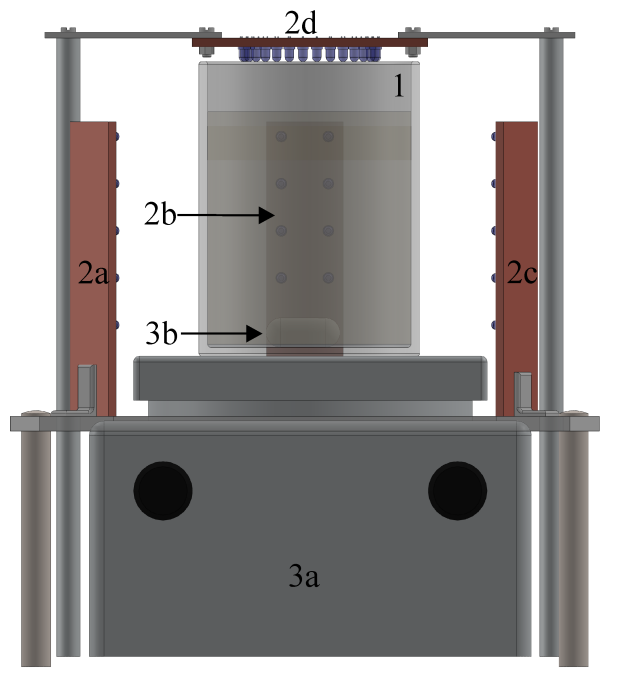

Fig. 4. Schematic diagram of photocatalytic reactors. A) UV-lamp photocatalytic reactor: 1) borosilicate vessel; 2a,b,c) UV-lamps; 3a) magnetic stirrer; 3b) magneto. B) Square UV-LED array photocatalytic reactor: 1) borosilicate vessel; 2a,b,c) square UV-LED arrays; 3a) magnetic stirrer; 3b) magneto. C) Radial UV-LED array photocatalytic reactor: 1) borosilicate vessel; 2) radial UV-LED array; 3a) magnetic stirrer; 3b) magneto. D) Square\&radial UVLED array photocatalytic reactor: 1) borosilicate vessel; 2a,b,c) square UV-LED arrays; 2d) radial UV-LED array; 3a) magnetic stirrer; 3b) magneto. 


\subsection{Photocatalytic degradation experiments}

In order to simulate the effluents after the dyeing process, $250 \mathrm{~mL}$ of distilled water were mixed with 0.1 $\mathrm{g} / \mathrm{L}$ of Orange PX-2R dye. Before photodegradation, the solution was mixed with $1 \mathrm{~g} / \mathrm{L}$ of photocatalyst in suspension and then the mixture was put on magnetic stirrer in complete darkness for 30 minutes to ensure the adsorption of the dye on the surface of the catalyst. After 30 minutes, the UV-light source was turned on with the mixture in constant agitation. The treatment was performed for 8 hours, and samples of were taken from the reactor every hour in order to determine the efficiency of the process.

The decolorization rate was measured to determine the efficiency of the treatment, and was calculated by:

$$
\text { Decolorization }(\%)=\left(\frac{A b s_{0}-A b s}{A b s_{0}}\right) \times 100
$$

where, $A b s_{0}$ is the initial absorbance, and $A b s$ is the absorbance at time $t$ of the taken sample. The absorbance was determined with a UV-visible spectrophotometer (UV-2401, Shimadzu Corporation) at the maximum wavelength of the visible spectrum $(\lambda=487 \mathrm{~nm})$.

\subsection{Energy consumption}

The power consumption of the AOPs for an experimental scenario, depends on different factors, such as the type of pollutant, type of light source, reactor configuration, among others. A quantitative comparison can be obtained in terms of Figures-of-merit, for the case of photocatalytic processes the efficiencies can be determined by means of the Figure-of-merit "Electric energy per order (Ево)", defined as the electric energy $(\mathrm{kW})$ needed to degrade a pollutant by one order of magnitude (90\%) in a unit volume of contaminated water $\left(1 \mathrm{~m}^{3}\right)$ (Bolton et al., 2001; Lanzarini-Lopes et al., 2017; Miklos et al., 2018).

EEO values $\left[\mathrm{kWh} / \mathrm{m}^{3} /\right.$ order $]$ can be calculated by:

$$
E_{E O}=\frac{(P)(t)(1000)}{(V)(60)\left(\log \left(C_{0} / C\right)\right)}
$$

where, $P$ is the electric power $(\mathrm{kW}), t$ is the time ( $\min ), V$ is the water treated volume (L), $C_{0}$ and $C$ are the initial and final concentrations of contaminant $(\mathrm{mol} / \mathrm{L})$. 


\section{Results and Discussion}

\subsection{Source characterization}

Angular emission measurements show that the LEDs have a reduced emission angle with respect to the lamps. In addition, these measurements provide the value of the angle $(\theta)$ to be used in the determination of the parameter $m$ as given in the Eq. (10).

The polar plot corresponding to the UV lamp represented in Fig. 5A shows an angular emission over $360^{\circ}$ with an emission pattern which is not homogeneous due to the particular geometry of the lamp, the emission being reduced by $50 \%$ when observed in the direction where the two tubes that compose the lamp are aligned. This type of lighting will not use the total irradiance generated by the lamp for the photocatalytic process, since part of the emitted light falls out of the limits of the reactor.

A)

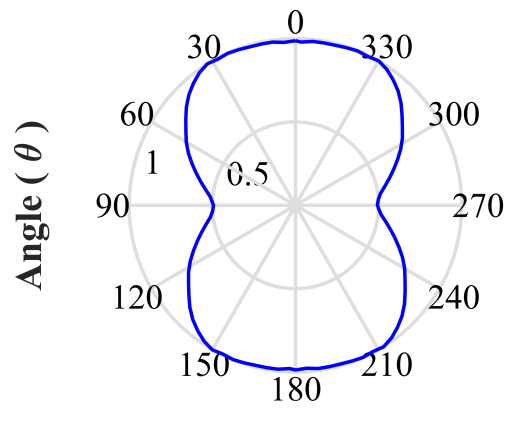

B)

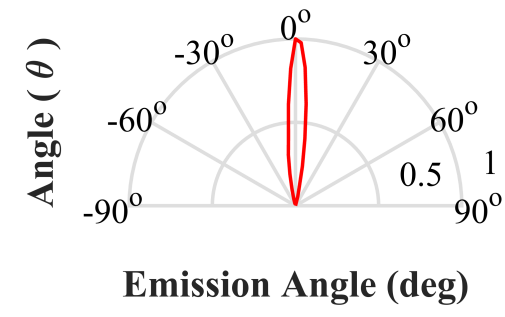

Emission Angle (deg)

Fig. 5. Normalized angular emission of sources measured at a distance of $10 \mathrm{~cm}$ from the photodetector. A) a lowpressure ultraviolet lamp B) An ultraviolet LED, measured at a distance of $10 \mathrm{~cm}$ respect to the photodetector.

In the case of the single LED, the angular emission also depends on its construction geometry; as can be seen in Fig. 5B, the light emission is limited to a certain angular range, which is lower than the emission angle of the lamps. Taking Eq. (9) as reference, the maximum emission occurs when the LED emits normally to the surface and decreases as the angle $\theta$ increases. The value of $m$ used in the equations of distribution of irradiance (Eqs. (11), (12)), is obtained from the half-maximum view angle measured experimentally $\theta_{1 / 2}= \pm 12^{\circ}$. For this experiment the result obtained was $m=31.37$. 
To verify the feasibility of the replacement of conventional UV lamp sources by the use of LED arrays by means of the proposed methodology, two steps were involved. First, the irradiance of an ultraviolet lamp was measured experimentally (along the direction of the maximum emission shown in Fig. 5A) as a function of the distance from the lamp. These results are plotted in Fig. 6 (circular marks), for distances ranging between $6-36 \mathrm{~cm}$. Secondly, the algorithm proposed in the previous section was used to generate the LED arrays matching the measured irradiance of the UV lamp at a specific distance; an square geometry scheme was selected, and once that the features of the arrays were obtained (i.e., their dimensions and number of LEDs) the irradiance values were calculated (Fig. 6, square marks) in order to compare them with the values of the lamp.

The differences between the irradiances of each light source (Fig. 6, error bars) are due to that the methodology to generate the arrays has as objective to match or exceed the $E_{\text {des }}$ value (i.e., the measured irradiance of the lamp), therefore, for some points an array could provide a higher irradiance than the required. Moreover, with the aim to corroborate mathematically that the results of each source have a direct relation, a trend curve was fitted to each source and the Pearson correlation coefficient was calculated, obtaining a result of 0.99 , which verifies that both sources performed similarly and satisfy the Inverse-squared law.

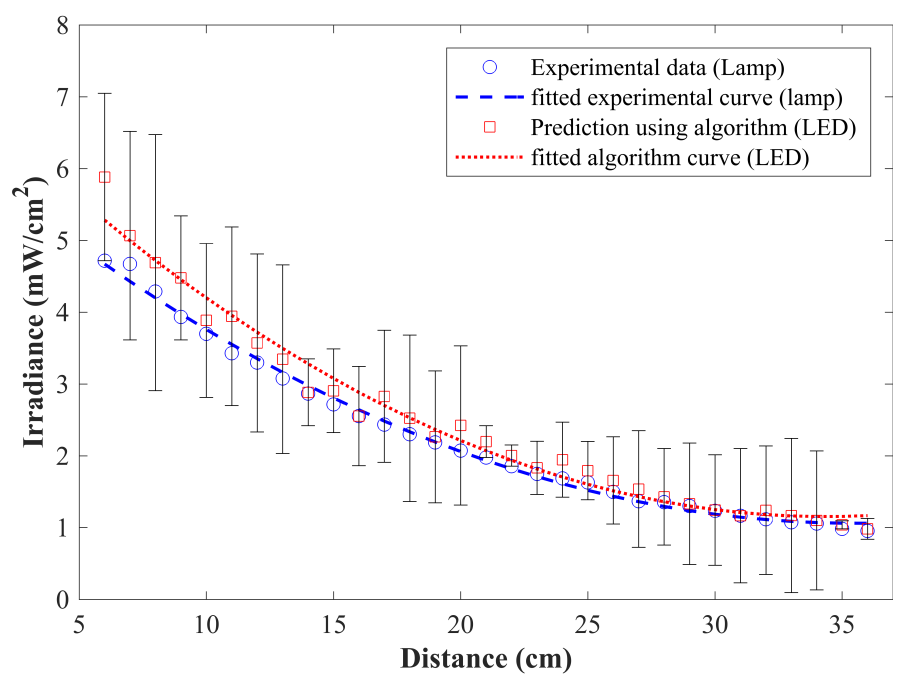

Fig. 6. Irradiance of a lamp measured experimentally vs irradiance prediction of different LED arrays using the proposed methodology, at different positions. Fitted curves show the trend of experimental and predicted irradiance. The error bars indicate the difference in irradiance. 
The performance of the heterogeneous photocatalysis process is associated to the use of a source of illumination that activates the photocatalyst. For the case of Degussa P-25 titanium dioxide, an ultraviolet source is necessary. The Fig. 7 shows the emission spectrum measured experimentally of the two different ultraviolet sources used in this work and their relation to the working area of $\mathrm{TiO}_{2}$ (defined by the shaded area). It can be observed that conventional UV-lamps emit over a broader frequency spectrum than the UV-LED, but only a part of the emitted energy falls within the active region of the photocatalyst, representing a waste of energy. As a counterpart, the UV-LED concentrates most of its energy in the working area of the photocatalyst, being highly efficient for the photocatalytic processes. However, since the emitted intensity of a single LED is smaller than the intensity of the UV-lamp, several LEDs are needed to reach the irradiance values of a conventional lamp, being the array configuration a key parameter in order to achieve comparable results.

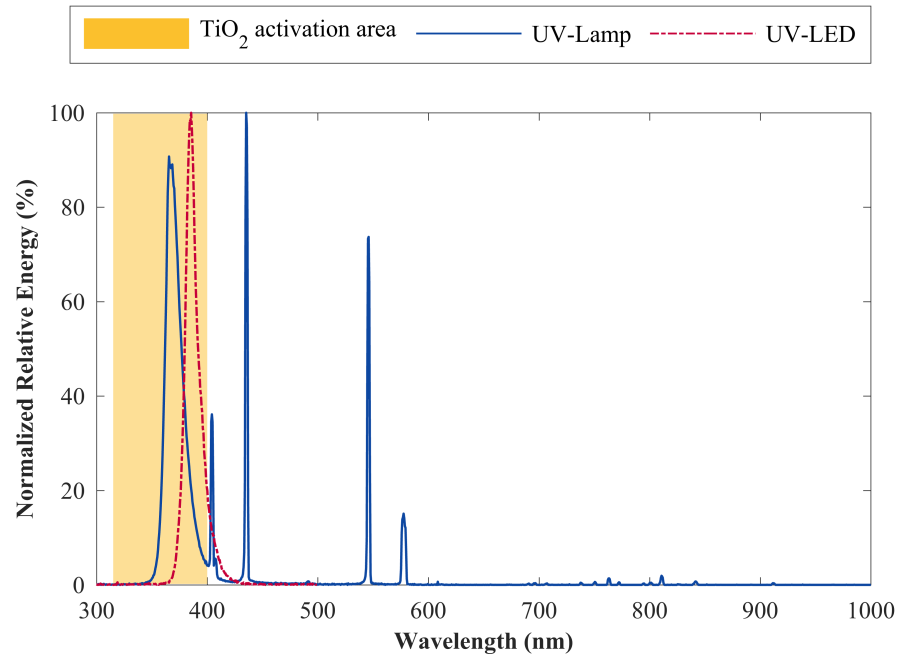

Fig. 7. Emission spectra of ultraviolet sources, and its relation to the activation area of titanium dioxide.

\subsection{LED array configuration}

The structures of arrays chosen for this study have been square and radial, as they are widely used for diverse lighting sources. In order to implement the square LED arrays, the direct replacement of a conventional lamp was obtained by setting the condition that the value of the irradiance of the lamp in the line at the center of the reactor should be equal to that generated by the LED array. The algorithm provides the least amount of LEDs providing this condition (Fig. 2). In the case of the radial structure, our imposed condition on the algorithm is to find uniform illumination distribution with a particular value of irradiance at the bottom zone of the reactor, to have a total reactor coverage (Fig. 3). 
The substitution of three UV-lamps in a cylindrical reactor of diameter $6.5 \mathrm{~cm}$ and height $8 \mathrm{~cm}$, can be implemented using three different UV-LED arrays, obtained using the proposed methods outlined in sections 2.1 and 2.2 .

The irradiance distribution of the UV-lamps at a distance of $10 \mathrm{~cm}$ from the source (corresponding to a transverse plane that crosses the center of the reactor) is shown in Fig. 8A, depicting a relatively homogeneous illumination with a maximum irradiance of $6 \mathrm{~mW} / \mathrm{cm}^{2}$ at the center, and decreasing to 5 $\mathrm{mW} / \mathrm{cm}^{2}$ towards the edges of the reactor.
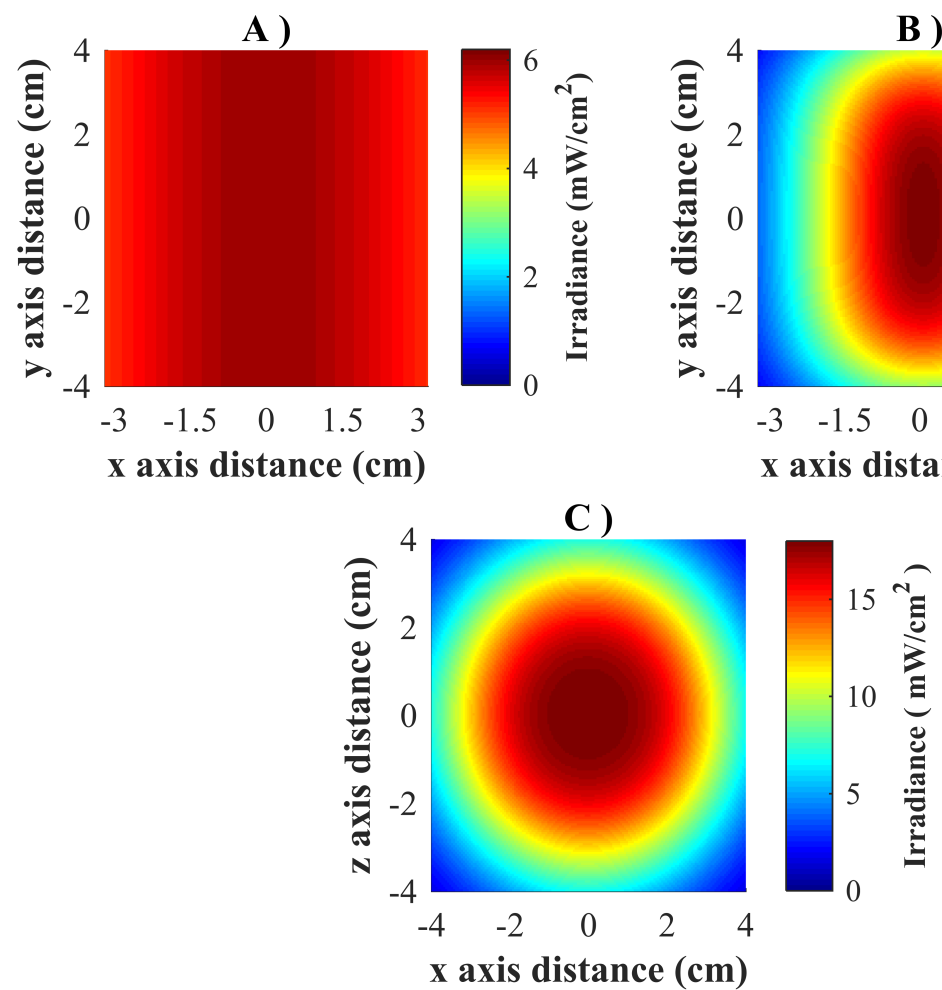
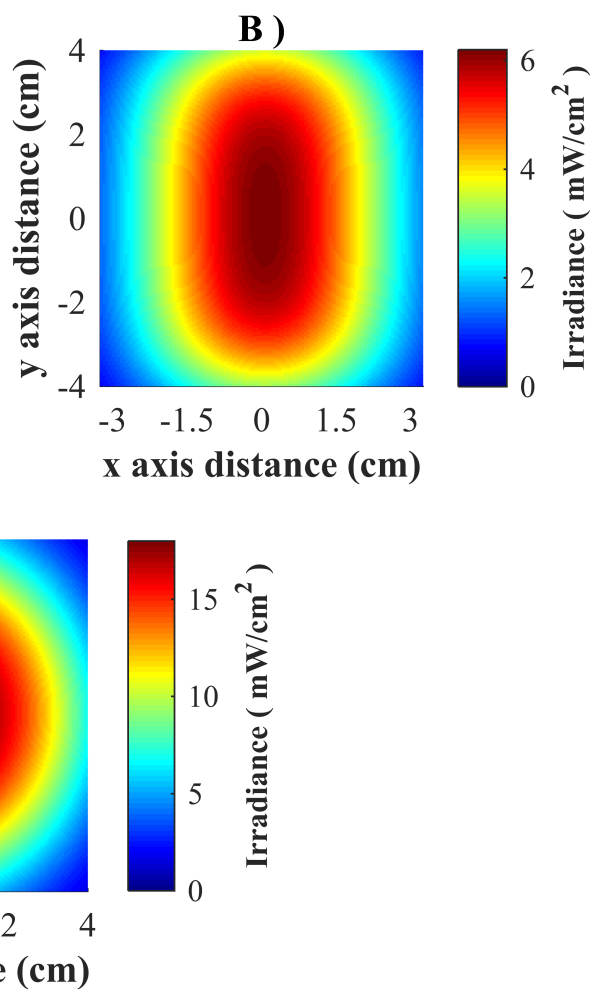

Fig. 8. Irradiance distribution of two sources. A) UV-lamp at a distance of $10 \mathrm{~cm}$ from the source B) a square array of $5 \times 2$ LEDs with $d=1.68 \mathrm{~cm}$ between elements, at a distance of $z=8 \mathrm{~cm}$ from the source, C) a radial array of 30 LEDs with $\rho=2.1 \mathrm{~cm}$, at a distance of $z=10 \mathrm{~cm}$ from the source.

The selected distance to place the square LED arrays was $z=8 \mathrm{~cm}$ to the center of the reactor (and not 10 $\mathrm{cm}$ as in the case of the UV-lamps by practical purposes in this setup). $E_{\text {des }}\left(6 \mathrm{~mW} / \mathrm{cm}^{2}\right)$ was defined by 
the maximum irradiance value of the UV-lamp at the point $(0,0)$ plotted in Fig. 8A. The results show that a square array of $2 \times 5$ LEDs separated by $d=1.68 \mathrm{~cm}$ between elements is needed to obtain the desired irradiance value at the selected point. In Fig. 8B, the distribution of irradiance in the transverse plane crossing the center of the reactor is plotted, and the results were obtained using the $m$ parameter value obtained from the experimental measurements $(m=31.37)$ and achieving a value of $6.16 \mathrm{~mW} / \mathrm{cm}^{2}$ for the $(0,0)$ point. A direct comparison between the intensities of both sources shows that the array configuration provides $87.7 \%$ of the UV lamp intensity over the reactor area. However the final photocatalytic efficiency will be provided by this and other additional factors such as the effect of the magnetic stirrer on the catalyst suspension distribution or the scattering of the generated light within the reactor. For the radial array, a value of $15 \mathrm{~mW} / \mathrm{cm}^{2}$ was stipulated as the maximum irradiance value (5 $\mathrm{mW} / \mathrm{cm}^{2}$ for each lamp to be replaced), measured at $10 \mathrm{~cm}$ from the bottom of the reactor. The generated radial array has $30 \mathrm{LEDs}$, with a radius of $2.1 \mathrm{~cm}$, a separation of $12^{\circ}$ between elements and a maximum irradiance of $18 \mathrm{~mW} / \mathrm{cm}^{2}$ (Fig. $8 \mathrm{C}$ ).

Since the emission patterns of the UV-LEDs and the UV-lamp are highly dissimilar (Fig. 5), it is evident that the irradiance pattern of the sources is not identical (Fig. 8). However, it can be seen that the main objective of the methodology was achieved, by having generated the same irradiance value for the LED array as for a lamp at the center of the reactor, and most of its physical area is covered by the irradiance pattern.

When the separation between LEDs is less than the optimal (i.e., by reducing their distance, or radius), the irradiance is increased but at expense of reducing its irradiation area, leading that the photocatalyst existing inside the reactor is not homogeneously illuminated and hindering its activation. Otherwise, the effect of a larger separation between individual elements results in non-uniform distribution and an overall decrease of the irradiance as well as in the photoactivity of the process.

The array distributions used in this study have been designed to obtain uniform illumination adapted to the geometry of a cylindrical reactor $8 \mathrm{~cm}$ high and $6.5 \mathrm{~cm}$ in diameter. Nonetheless, it is important to stress the point that the methodology proposed and the use of LEDs provides a versatility not provided by conventional lamps. The optimal LEDs distribution could be found in order to match the lighting 
requirements of different reactor geometries to cover the areas where the contaminant is located. The square array distributes the lighting uniformly throughout the reactor's vertical direction, but the resulting intensity decreases with the propagation distance, which makes it more useful for reactors with a height greater than the diameter (Fig. 8B); in the case of reactors with a diameter greater than the height, the array distribution that can be better adapted for uniform distribution would be the radial (Fig. 8C) distribution or a combination of both. Extending this idea other illumination distributions as a uniform LED distribution over the walls of the reactor could be considered.

\subsubsection{LED array implementation}

Fig. 9 shows the distribution of the implemented arrays. The square LED array of Fig. 9A replaces a single ultraviolet lamp, only containing 10 LEDs, with a distribution of $2 \times 5$ pieces and a distance of 1.68 $\mathrm{cm}$ between them. The radial LED array of Fig. 9B with radius of $2.1 \mathrm{~cm}$, and a separation of $12^{\circ}$ between elements, is able to replace the three lamps with a single array of 30 pieces, and has been designed to radiate $10 \mathrm{~cm}$ from the bottom of the reactor.
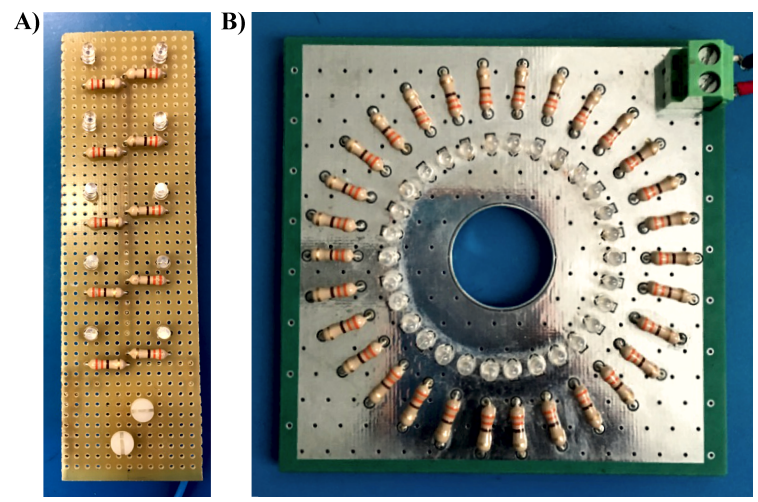

Fig. 9. Distribution of the implemented arrays. A) Square LED array $2 x 5$, B) Radial LED array.

Fig. 10 shows the different experimental photoreactors used in this study. The Fig. 10A is the reactor with 3 ultraviolet lamps, in Fig. 10B the reactor uses 3 square LED arrays presented in Fig. 9A, the Fig. 10C shows the reactor using the radial LED array of Fig. 9B, and finally the reactor in Fig. 10D use all designed LED arrays (squares and radial). The reactors presented were implemented with the characteristics mentioned in section 2.5 , and during their operation, they were maintained only with the light source selected, blocking any other spurious light that could affect the process. 

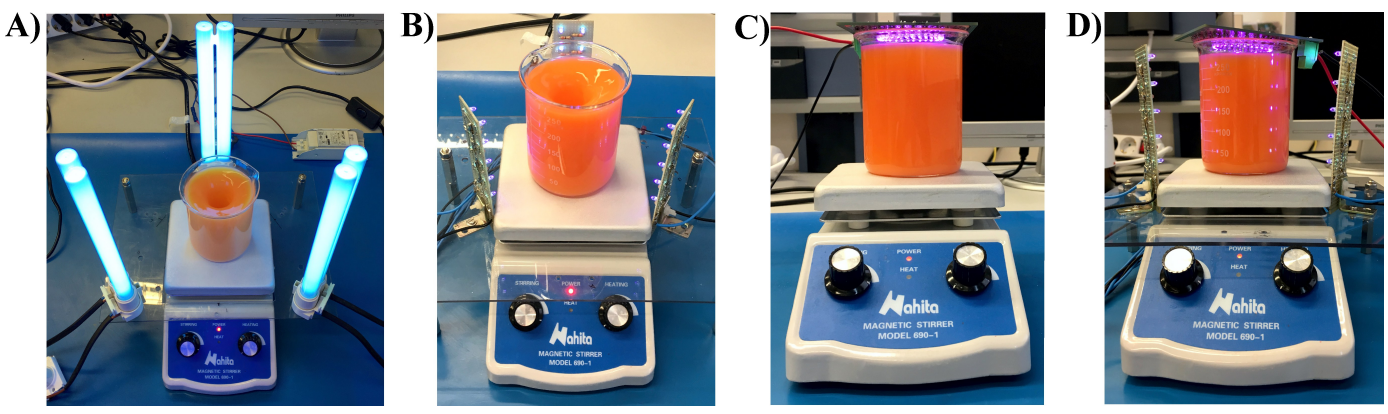

Fig. 10. Experimental reactors. A)Reactor with UV-lamps, B) Reactor with square LED arrays, C) Reactor with a radial LED array, D) Reactor with all UV-LEDs.

\subsection{Efficiency of the process to treat effluents containing reactive dyes}

\subsubsection{Photocatalytic activity}

Four configurations were tested: i) The UV-lamp configuration shown in Fig. 10A; ii) A configuration using only the three square LED arrays (Fig. 10B); iii) A configuration including only the top radial distribution of LEDs (Fig. 10C), and iv) The configuration with all LEDs is shows in Fig. 10D.

With the aim to perform the comparison of the dye degradation, all the samples were prepared under the same experimental conditions. It was corroborated prior to the photodegradation that the photocatalyst does not have the ability to degrade the dye without an UV-source.

As it can be seen in Fig. 11A, the performed experiments by the four analyzed configurations reached more than $90 \%$ of decolorization, which is the percentage necessary to calculate the Figure-of-merit $\mathrm{E}_{\mathrm{EO}}$.

The required time for the LED arrays configurations to reach this decolorization percentage is in all cases larger than the consumed by conventional lamps and in the last case (array with the highest number of elements) a full decolorization is achieved 20 minutes before than for the treatment with conventional lamps. In particular, it was observed that the time needed to achieve $90 \%$ decolorization was $1.74,1.55$ and 1.28 times longer than the UV lamp process for the ii), iii), and iv) UV-LED configurations respectively. However, when the process is considered also in terms of energy consumption this excess of time in the oxidation process can be compensated by the increased energetic efficiency of the process. 

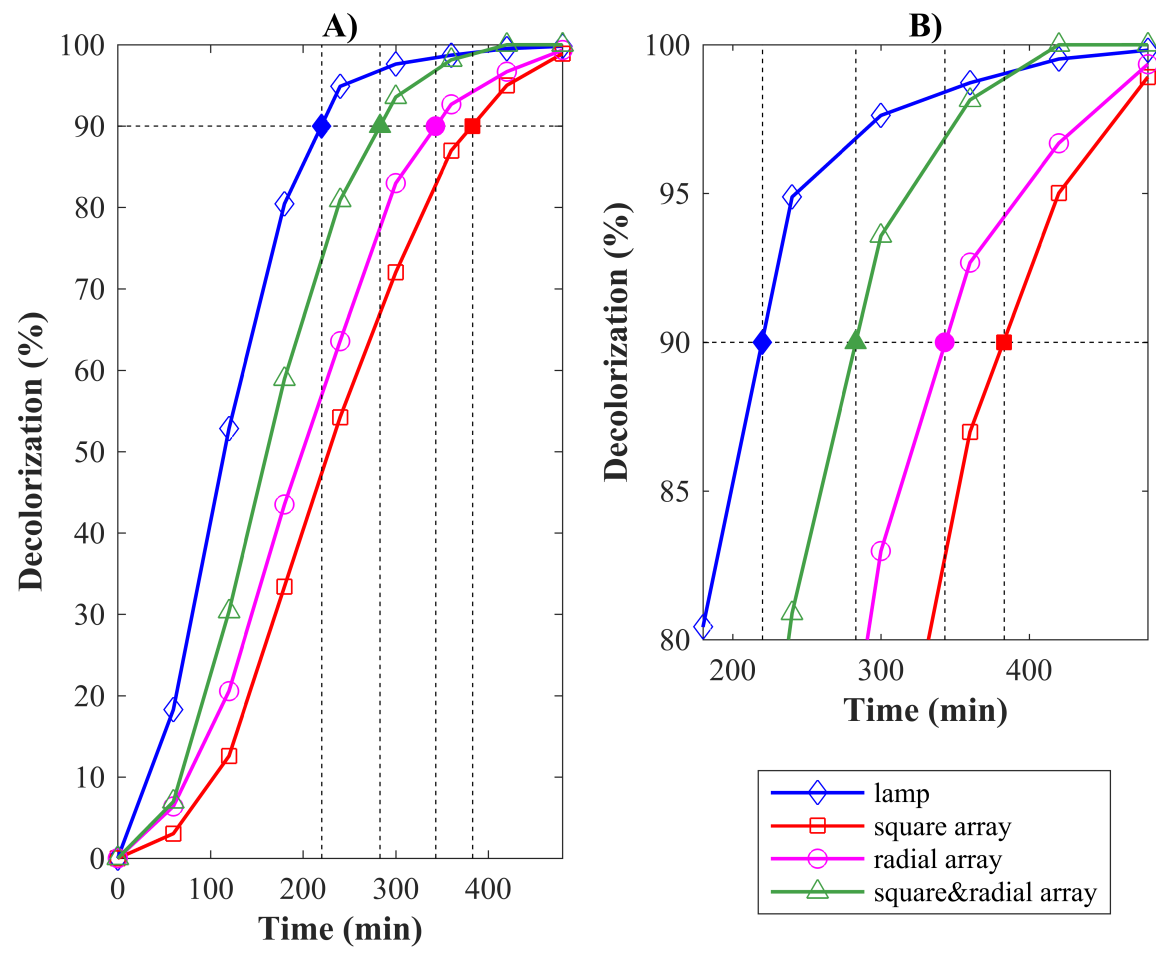

Fig. 11. Decolorization for the Orange PX-2R dye with different types of UV-sources, with a same initial concentration of $0.1 \mathrm{~g} / \mathrm{L}$ of dye and $1 \mathrm{~g} / \mathrm{L}$ of photocatalyst. A) Complete decolorization curve from 0 to $480 \mathrm{~min}$, B) Zoom in the zone from 180 to $480 \mathrm{~min}$.

A closer analysis of our particular experimental reactor's conditions can provide some ideas about the results obtained. The magnetic stirring used for catalyst homogenization in the liquid created a vortex at the center of the reactor, where the illumination from the square array and lamps is more similar and decreasing the efficiency of the LED array. The radial illumination in this case provides a more uniform illumination over the liquid area. The combination of both illumination systems provides an overall illumination covering all regions of the reactor and compensating the effect of the stirrer. Hence the geometry with more LEDs approaches more efficiently the operation of the conventional UV reactor.

\subsubsection{Kinetic analysis}

Kinetic rates obtained in the different experiments are shown in Fig. 12. As can be observed, the dye degradation in all cases follows a first-order kinetic model of Langmuir - Hinshelwood. This model provides the kinetic values $(\mathrm{K})$, calculated from the slope of logarithmic absorbance values versus time of treatment, and the regression coefficients $\left(\mathrm{R}^{2}\right)$. 


\begin{tabular}{|lll}
\hline lamp & $\square$ & $\begin{array}{l}\text { square } \\
\text { array }\end{array}$
\end{tabular}$\quad \begin{aligned} & \text { radial } \\
& \text { array }\end{aligned} \Delta$\begin{tabular}{l}
$\begin{array}{l}\text { square\&radial } \\
\text { array }\end{array}$ \\
\hline
\end{tabular}

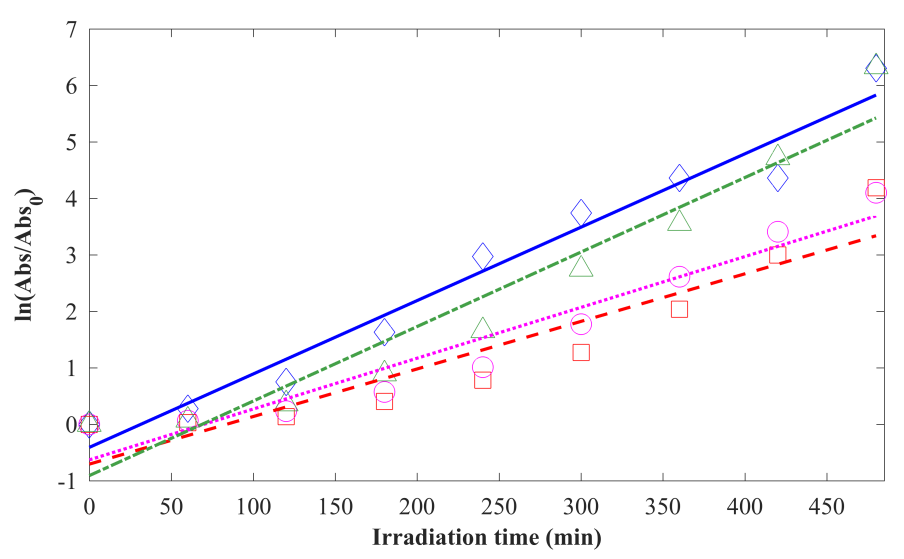

Fig. 12. Relation between $\ln \left(\mathrm{Abs}_{\mathrm{Abs}}\right)$ and irradiation time, with a same initial concentration of $0.1 \mathrm{~g} / \mathrm{L}$ of dye and $1 \mathrm{~g} / \mathrm{L}$ of photocatalyst.

The values corresponding to the regression coefficients $\left(\mathrm{R}^{2}\right)$, as well as the kinetic degradation rate $(\mathrm{K})$ are listed in Table 1. The results indicate that the rate of kinetic degradation decreases for the cases with LED lighting with fewer pieces (square and radial arrays, 30 LEDs) while the values using lamp and the array with more pieces (square\&radial array, 60 LEDs) are similar.

Table 1. The first-order degradation rate constant, and Costs for the decolorization of Orange PX-2R dye by different UV-sources.

\begin{tabular}{llll}
\hline $\mathbf{U V}-$ source & $\mathbf{R}^{\mathbf{2}}$ & $\mathbf{K}\left(\mathbf{m i n}^{-\mathbf{1}}\right)$ & $\begin{array}{c}\text { Electrical cost } \\
\left(\mathbf{E} / \mathbf{m}^{\mathbf{3}}\right)\end{array}$ \\
\hline Lamp & 0.9664 & 0.0130 & 152.62 \\
Square LED array & 0.8764 & 0.0084 & 29.60 \\
Radial LED array & 0.9338 & 0.0090 & 26.36 \\
Square\&radial LED array & 0.9341 & 0.0132 & 43.62 \\
\hline
\end{tabular}

With the aim to corroborate the repeatability of the proposed methodology, several experiments with identical initial conditions have been performed. The results show that for the case of square plus radial illumination the maximum relative error of the observed degradation time in the different measurements is less than $5 \%$, giving an average value of $\mathrm{K}=0.0139$. Furthermore, the results obtained for $\mathrm{K}$ in the 
degradation process using conventional lamps confronted with our proposed LED distribution show a relative error less than $7 \%$.

In addition, these results suggest that a relationship exists between the lighting pattern of the source and its area of illumination. The lamp by having a wider lighting pattern covers a larger area in the reactor than the LED arrays. However, by joining the square and radial LED arrays the illuminated area of the reactor increases as well and the $\mathrm{R}^{2}$ and $\mathrm{K}$ values obtained from the lamp are nearly matched. A direct comparison is however not easily evaluable due to other effects influencing the final illumination of the suspended catalysts.

With the aim to present in economic terms the results obtained for different ultraviolet sources and their configurations, the electrical cost of the processes was calculated. This cost was calculated considering the rate of the electric power for industrial use in Spain for the year $2018(0.19270 € / \mathrm{kWh})$. Table 1 shows the cost of each process when reaching $90 \%$ of the decolorization.

As can be seen in Table 1, all photocatalytic processes using LED arrays require less electrical power and are related to the number of LEDs contained in the array. However, the array with more LED elements only increases the cost by $33 \%$ than the radial LED array, and reduces the time of the photocatalytic process in one hour.

\subsubsection{Energy consumption analysis}

In general, the results reported in the literature rarely compare the performance between conventional lamps and LEDs, which makes a direct comparison difficult. Therefore, it is necessary to consider various operating parameters as the type of pollutant and its concentration, the source of illumination, the characteristics of the reactor, the photocatalyst among others. Nevertheless, the EEO can enable a performance measurement with the aim to compare the efficiency in terms of energy consumption.

In order to perform the analysis of the energetic consumption with regard to the photocatalytic processes, the Figure-of-merit $E_{\mathrm{EO}}$ was used and $90 \%$ of degradation values were considered (Fig. 11A). As it was observed in the photocatalytic activity results, decolorization by conventional ultraviolet lamps is the first to reach $90 \%$, however, the $\mathrm{E}_{\mathrm{EO}}$ values are significantly far convenient with the use of the implemented 
LED arrays by means of the proposed methodology (Table 2), since conventional lamps considerably require more electrical power to carry out the photocatalytic process. According to the results, the experiments carried out with the array with the highest number of LEDs provided similar results that those performed with the conventional UV-lamps, but reducing the energy consumption $72 \%$.

Table 2 shows the EEO values reported in the literature to degrade different pollutant by means of advanced oxidation processes.

For the case of the UV-LED/ $\mathrm{TiO}_{2} /$ dye processes two tendencies are manifested, i) implementations with more LEDs than the arrays proposed in this study and ii) implementations with fewer elements of LEDs. For both cases, the arrays generated by this methodology require a lesser amount of electrical power. For i) the amount of electric energy decreases about $20-45 \%$, and for ii) the electric energy consumed by the optimized arrays only requires between $5-15 \%$ of the total energy by other arrays, depending on the type of array chosen (30 or 60 LEDs) for both cases.

As for the experimental scenarios proposed in this study, it can be noticed that the optimized LED arrays only require between $10-28 \%$ of the energy consumed by ultraviolet lamps to decolorate the same amount of water, the $\mathrm{E}_{\mathrm{EO}}$ value of this photoreactor indicates an energy saving since with the same amount of energy it is possible to decolorize an amount of 3.5 times more water than conventional lamps.

Comparing the EEO values of this study with those provided by (Muruganandham et al., 2007) using lamps would require between $25.63 \%$ and $82.18 \%$ more Electrical Energy per order.

Furthermore, the results using LED arrays indicate that with respect to (Ferreira et al., 2016), 41.16\% is saved when using the square arrays (30 LEDs), 45.89\% with the radial array (30 LEDs) and 19.04\% using the square \& radial configuration (60 LEDs). With respect to (K. Natarajan et al., 2011), 83.60\% and $84.92 \%$ are saved using the square and radial arrangements respectively (30 LEDs per configuration) and $77.44 \%$ using the square \& radial arrangement (60 LEDs). 
Table 2. Comparison of $\mathrm{E}_{\mathrm{EO}}$ values with literature.

\begin{tabular}{|c|c|c|c|c|}
\hline Source & $\begin{array}{l}\text { Treatment } \\
\text { Process }\end{array}$ & Contaminant & $\begin{array}{l}\text { Eeo Value } \\
\left(\mathrm{kWh} / \mathrm{m}^{3} / \text { order }\right)\end{array}$ & Author \\
\hline \multicolumn{5}{|l|}{ Lamp } \\
\hline 8 mp-lamps $(8 \mathrm{~W})$ & Photo-Fenton & Reactive Orange 4 & 357.10 & (Muruganandham et al., 2007) \\
\hline 1 lp-lamp (30W) & UV & Insecticide diazinon & $20,000.00$ & (Daneshvar et al., 2007) \\
\hline 8 mp-lamps (8W) & $\mathrm{UV} / \mathrm{H}_{2} \mathrm{O}_{2}$ & Reactive Orange 4 & $1,666.00$ & (Muruganandham et al., 2007) \\
\hline $8 \mathrm{mp}$-lamps $(8 \mathrm{~W})$ & $\mathrm{UV} / \mathrm{H}_{2} \mathrm{O}_{2}$ & Reactive Yellow 14 & $2,000.00$ & (Muruganandham et al., 2007) \\
\hline $1 \mathrm{mp}$-lamp (150W) & $\mathrm{UV} / \mathrm{TiO}_{2}$ & SDBS & 595.00 & (Dominguez et al., 2016) \\
\hline 8 mp-lamps (8W) & $\mathrm{UV} / \mathrm{TiO}_{2}$ & Reactive Orange 4 & 500.00 & (Muruganandham et al., 2007) \\
\hline 8 mp-lamps (8W) & $\mathrm{UV} / \mathrm{TiO}_{2}$ & Reactive Yellow14 & 344.80 & (Muruganandham et al., 2007) \\
\hline 3 lp-lamp (18W) & $\mathrm{UV} / \mathrm{TiO}_{2}$ & Orange PX-2R & 628.14 & {$[*]$} \\
\hline \multicolumn{5}{|l|}{ LED } \\
\hline 15 LEDs (390-410nm) & $\mathrm{UV} / \mathrm{TiO}_{2}$ & Malachite Green & 789.47 & (K. Natarajan et al., 2011) \\
\hline 15 LEDs (390-410nm) & $\mathrm{UV} / \mathrm{TiO}_{2}$ & Methylene Blue & 3000.00 & (K. Natarajan et al., 2011) \\
\hline 15 LEDs (390-410nm) & $\mathrm{UV} / \mathrm{TiO}_{2}$ & Rhodamine B & 1500.00 & (K. Natarajan et al., 2011) \\
\hline 384 LEDs (395nm) & $\mathrm{UV} / \mathrm{TiO}_{2}$ & O-cresol & 37.00 & (Chen et al., 2007) \\
\hline 180 LEDs $(375-380 \mathrm{~nm})$ & $\mathrm{UV} / \mathrm{TiO}_{2}$ & SDBS & 640.00 & (Dominguez et al., 2016) \\
\hline 4 LEDs $(390-410 \mathrm{~nm})$ & UV/TNA-300 & Congo red & 228.00 & (T. S. Natarajan et al., 2011) \\
\hline 4 LEDs $(390-410 \mathrm{~nm})$ & UV/TNA-500 & Congo red & 317.00 & (T. S. Natarajan et al., 2011) \\
\hline 4 LEDs (390-410nm) & UV & Congo red & $14,285.00$ & (T. S. Natarajan et al., 2011) \\
\hline 6 LEDs $(360 \mathrm{~nm})$ & UV/Peroxydisulfate & Basic Red 46 & 155.40 & (Rasoulifard et al., 2011) \\
\hline
\end{tabular}

$[*]$ experimental results for this work

It can be observed that in general the use of LEDs reduces the energy consumption of the treatment in comparison to the use of conventional UV-lamps. However, it is important to highlight that in some cases the consumption obtained is equal or even higher. This could be attributed to the fact that the distribution of the LEDs was not optimized during the treatment. 


\section{Conclusions}

In this study uniform irradiance models were applied in order to create a methodology to calculate optimized LED arrays, considering the photochemical requirements of the photocatalytic reactor used in the decolorization of textile dyes.

As is noted, the use of conventional lamps leads to an inefficiency of the photocatalytic process, since the photocatalyst does not take advantage of all the energy emitted by the lamp, which produces an over consumption of energy or the need to modify the chemical characteristics of the photocatalyst. Although some possible improvements could be devised such as placing special mirrors with the intention of collecting the non-directed irradiance towards the reactor, it has been demonstrated that the use of LED arrays can effectively reduce the cost of the process.

The use of LEDs could help to reduce the necessary energy to carry out the photocatalysis process (with the implicit benefits of the LED sources as lifetime, avoiding the use of mercury lighting sources), but if the LED arrays are not carefully optimized the reduction in electricity consumption cannot be assured, and the adding LEDs could counterproductively increase the cost of the process (as well as the cost of the implementation), thus, an improvement in photocatalytic results is not guaranteed. In this study, by emphasizing the minimum number of elements as well as their optimal distribution for the LED arrays with regard to the physical dimensions of the reactor, the obtained results show that a diminishing on the energy consumption for the photocatalytic process up to $90 \%$ can be achieved.

When the square\&radial configuration (60 LEDs) was used, the decolorization time was reduced with respect to the square or radial configurations, increasing only a $5 \%$ the electrical energy per order with respect to the configuration using 30 LEDs. In addition, the total decolorization time was achieved before the setting using lamps (Fig. 11B) using less than $30 \%$ of the energy required by the lamps.

In future studies, further improvements could be introduced: i) analyze optimized LED arrays whose wavelengths are located in the middle zone of the activation area of titanium dioxide could be advantageous since most of the currently implemented processes make use of LEDs whose wavelength is 
at the boundary activation area of the photocatalyst; ii) analyze the relationship between the irradiance of the different configurations presented in this work (radial, square and square\&radial) and the relative absorbance of the catalyst using a reactor with immobilized photocatalyst without magnetic stirring to ensure the presence of wastewater in the reactor core or iii) study LED configurations whose irradiance pattern may be non-uniform or can be concentrated at the edges of the reactor, since these areas may contain significant amounts of photocatalyst in suspension.

\section{Acknowledgments}

The authors are grateful for the scholarship grant for the author Tecilli Tapia (417993) from National Council of Science and Technology of Mexico (CONACyT), and the Laboratory of Environmental Pollution Control of INTEXTER, for the material provided.

\section{References}

Ahmad, A.L., Puasa, S.W., 2007. Reactive dyes decolourization from an aqueous solution by combined coagulation/micellar-enhanced ultrafiltration process. Chem. Eng. J. 132, 257-265. https://doi.org/10.1016/j.cej.2007.01.005

Bilal, M., Rasheed, T., Iqbal, H.M.N., Li, C., Wang, H., Hu, H., Wang, W., Zhang, X., 2018. Photocatalytic degradation, toxicological assessment and degradation pathway of C.I. Reactive Blue 19 dye. Chem. Eng. Res. Des. 129, 384-390. https://doi.org/10.1016/j.cherd.2017.11.040

Bilińska, L., Gmurek, M., Ledakowicz, S., 2016. Comparison between industrial and simulated textile wastewater treatment by AOPs - Biodegradability, toxicity and cost assessment. Chem. Eng. J. 306, 550-559. https://doi.org/10.1016/j.cej.2016.07.100

Bolton, J.R., Bircher, K.G., Tumas, W., Tolman, C.A., 2001. Figures-of-merit for the technical development and application of advanced oxidation technologies for both electric- and solar-driven systems (IUPAC Technical Report). Pure Appl. Chem. 73, 627-637. https://doi.org/10.1351/pac200173040627

Buscio, V., Brosillon, S., Mendret, J., Crespi, M., Gutiérrez-Bouzán, C., 2015. Photocatalytic Membrane Reactor for the Removal of C.I. Disperse Red 73. Materials (Basel). 8, 3633-3647. https://doi.org/10.3390/ma8063633

Chen, H.C., Wu, G.Y., 2010. Investigation of irradiance efficiency for LED phototherapy with different 
arrays. Opt. Commun. 283, 4882-4886. https://doi.org/10.1016/j.optcom.2010.07.055

Chen, H.W., Ku, Y., Irawan, A., 2007. Photodecomposition of o-cresol by UV-LED/TiO 2 process with controlled periodic illumination. Chemosphere 69, 184-190.

https://doi.org/10.1016/j.chemosphere.2007.04.051

Chong, M.N., Jin, B., Chow, C.W.K., Saint, C., 2010. Recent developments in photocatalytic water treatment technology: a review. Water Res. 44, 2997-3027. https://doi.org/10.1016/j.watres.2010.02.039

Daneshvar, N., Aber, S., Seyed Dorraji, M.S., Khataee, A.R., Rasoulifard, M.H., 2007. Photocatalytic degradation of the insecticide diazinon in the presence of prepared nanocrystalline $\mathrm{ZnO}$ powders under irradiation of UV-C light. Sep. Purif. Technol. 58, 91-98. https://doi.org/10.1016/j.seppur.2007.07.016

Dominguez, S., Rivero, M.J., Gomez, P., Ibañez, R., Ortiz, I., 2016. Kinetic modeling and energy evaluation of sodium dodecylbenzenesulfonate photocatalytic degradation in a new LED reactor. J. Ind. Eng. Chem. 37, 237-242. https://doi.org/10.1016/j.jiec.2016.03.031

Ferreira, L.C., Lucas, M.S., Fernandes, J.R., Tavares, P.B., 2016. Photocatalytic oxidation of Reactive Black 5 with UV-A LEDs. J. Environ. Chem. Eng. 4, 109-114. https://doi.org/10.1016/j.jece.2015.10.042

Gaya, U.I., Abdullah, A.H., 2008. Heterogeneous photocatalytic degradation of organic contaminants over titanium dioxide: A review of fundamentals, progress and problems. J. Photochem. Photobiol. C Photochem. Rev. 9, 1-12. https://doi.org/10.1016/j.jphotochemrev.2007.12.003

Ghosh, J.P., Sui, R., Langford, C.H., Achari, G., Berlinguette, C.P., 2009. A comparison of several nanoscale photocatalysts in the degradation of a common pollutant using LEDs and conventional UV light. Water Res. 43, 4499-4506. https://doi.org/10.1016/j.watres.2009.07.027

Gümüş, D., Akbal, F., 2011. Photocatalytic Degradation of Textile Dye and Wastewater. Water, Air, Soil Pollut. 216, 117-124. https://doi.org/10.1007/s11270-010-0520-z

Herrmann, J.-M., 1999. Heterogeneous photocatalysis: fundamentals and applications to the removal of various types of aqueous pollutants. Catal. Today 53, 115-129. https://doi.org/10.1016/S09205861(99)00107-8

Herrmann, J.M., 2005. Heterogeneous photocatalysis: State of the art and present applications. Top. Catal. 34, 49-65. https://doi.org/10.1007/s11244-005-3788-2 
Holkar, C.R., Jadhav, A.J., Pinjari, D. V., Mahamuni, N.M., Pandit, A.B., 2016. A critical review on textile wastewater treatments: Possible approaches. J. Environ. Manage. 182, 351-366. https://doi.org/10.1016/j.jenvman.2016.07.090

Jamali, A., Vanraes, R., Hanselaer, P., Van Gerven, T., 2013. A batch LED reactor for the photocatalytic degradation of phenol. Chem. Eng. Process. Process Intensif. 71, 43-50. https://doi.org/10.1016/j.cep.2013.03.010

Jo, W.K., Tayade, R.J., 2014a. New generation energy-efficient light source for photocatalysis: LEDs for environmental applications. Ind. Eng. Chem. Res. 53, 2073-2084. https://doi.org/10.1021/ie404176g

Jo, W.K., Tayade, R.J., 2014b. Recent developments in photocatalytic dye degradation upon irradiation with energy efficient light emitting diodes. Chinese J. Catal. 35, 1781-1792. https://doi.org/10.1016/S1872

Khezrianjoo, S., Revanasiddappa, H.D., 2016. Effect of operational parameters and kinetic study on the photocatalytic degradation of m-cresol purple using irradiated $\mathrm{ZnO}$ in aqueous medium. Water Qual. Res. J. Canada 51, 69-78. https://doi.org/10.2166/wqrjc.2015.028

Kim, S.H., Lee, S.W., Lee, G.M., Lee, B.T., Yun, S.T., Kim, S.O., 2016. Monitoring of TiÖ-catalytic UV-LED photo-oxidation of cyanide contained in mine wastewater and leachate. Chemosphere 143, 106-114. https://doi.org/10.1016/j.chemosphere.2015.07.006

Lanzarini-Lopes, M., Garcia-Segura, S., Hristovski, K., Westerhoff, P., 2017. Electrical energy per order and current efficiency for electrochemical oxidation of p-chlorobenzoic acid with boron-doped diamond anode. Chemosphere 188, 304-311. https://doi.org/10.1016/j.chemosphere.2017.08.145

Matafonova, G., Batoev, V., 2018. Recent advances in application of UV light-emitting diodes for degrading organic pollutants in water through advanced oxidation processes: A review. Water Res. 132, 177-189. https://doi.org/10.1016/j.watres.2017.12.079

McCullagh, C., Skillen, N., Adams, M., Robertson, P.K.J., 2011. Photocatalytic reactors for environmental remediation: A review. J. Chem. Technol. Biotechnol. 86, 1002-1017. https://doi.org/10.1002/jctb.2650

Meerbergen, K., Crauwels, S., Willems, K.A., Dewil, R., Van Impe, J., Appels, L., Lievens, B., 2017. Decolorization of reactive azo dyes using a sequential chemical and activated sludge treatment. J. Biosci. Bioeng. 124, 668-673. https://doi.org/10.1016/j.jbiosc.2017.07.005 
Miklos, D.B., Remy, C., Jekel, M., Linden, K.G., Drewes, J.E., Hübner, U., 2018. Evaluation of advanced oxidation processes for water and wastewater treatment - A critical review. Water Res. 139, 118131. https://doi.org/10.1016/j.watres.2018.03.042

Moreno, I., Tzonchev, R.I., 2006. Designing light-emitting diode arrays for uniform near-field irradiance. Appl. Opt. 45, 2265-2272.

Muruganandham, M., Selvam, K., Swaminathan, M., 2007. A comparative study of quantum yield and electrical energy per order (EEO) for advanced oxidative decolourisation of reactive azo dyes by UV light. J. Hazard. Mater. 144, 316-322. https://doi.org/10.1016/j.jhazmat.2006.10.035

Natarajan, K., Natarajan, T.S., Bajaj, H.C., Tayade, R.J., 2011. Photocatalytic reactor based on UV$\mathrm{LED} / \mathrm{TiO}_{2}$ coated quartz tube for degradation of dyes. Chem. Eng. J. 178, 40-49. https://doi.org/10.1016/j.cej.2011.10.007

Natarajan, T.S., Natarajan, K., Bajaj, H.C., Tayade, R.J., 2011. Energy efficient UV-LED source and $\mathrm{TiO}_{2}$ nanotube array-based reactor for photocatalytic application. Ind. Eng. Chem. Res. 50, 77537762. https://doi.org/10.1021/ie200493k

Ozturk, E., Koseoglu, H., Karaboyaci, M., Yigit, N.O., Yetis, U., Kitis, M., 2016. Sustainable textile production: cleaner production assessment/eco-efficiency analysis study in a textile mill. J. Clean. Prod. 138, 248-263. https://doi.org/10.1016/j.jclepro.2016.02.071

Ramane, D., Shaligram, A., 2011. Optimization of multi-element LED source for uniform illumination of plane surface. Opt. Express 19 Suppl 4, A639-A648. https://doi.org/10.1364/OE.19.00A639

Rasoulifard, M.H., Marandi, R., Majidzadeh, H., Bagheri, I., 2011. Ultraviolet Light-Emitting Diodes and Peroxydisulfate for Degradation of Basic Red 46 from Contaminated Water. Environ. Eng. Sci. 28, 229-235. https://doi.org/10.1089/ees.2010.0202

Repo, E., Rengaraj, S., Pulkka, S., Castangnoli, E., Suihkonen, S., Sopanen, M., Sillanpaa, M., 2013. Photocatalytic degradation of dyes by CdS microspheres under near UV and blue LED radiation. Sep. Purif. Technol. 120, 206-214. https://doi.org/10.1016/j.seppur.2013.10.008

Riga, A., Soutsas, K., Ntampegliotis, K., Karayannis, V., Papapolymerou, G., 2007. Effect of system parameters and of inorganic salts on the decolorization and degradation of Procion H-exl dyes. Comparison of $\mathrm{H}_{2} \mathrm{O}_{2} / \mathrm{UV}$, Fenton, UV/Fenton, $\mathrm{TiO}_{2} / \mathrm{UV}$ and $\mathrm{TiO}_{2} / \mathrm{UV} / \mathrm{H}_{2} \mathrm{O}_{2}$ processes. Desalination 211, 72-86. https://doi.org/10.1016/j.desal.2006.04.082

Shie, J.L., Lee, C.H., Chiou, C.S., Chang, C.T., Chang, C.C., Chang, C.Y., 2008. Photodegradation 
kinetics of formaldehyde using light sources of UVA, UVC and UVLED in the presence of composed silver titanium oxide photocatalyst. J. Hazard. Mater. 155, 164-172. https://doi.org/10.1016/j.jhazmat.2007.11.043

Su, Z., Xue, D., Ji, Z., 2012. Designing LED array for uniform illumination distribution by simulated annealing algorithm. Opt. Express 20, A843. https://doi.org/10.1364/OE.20.00A843

Tapia-Tlatelpa, T., Trull, J., Romeral, L., 2019. In situ Decolorization Monitoring of Textile Dyes for an Optimized UV-LED/TiO2 Reactor. Catalysts 9, 669. https://doi.org/10.3390/catal9080669

Tokode, O., Prabhu, R., Lawton, L.A., Robertson, P.K.J., 2015. UV LED Sources for Heterogeneous Photocatalysis, in: Bahnemann, D.W., Robertson, P.K.J. (Eds.), Environmental Photochemistry Part III. Springer- Verlag Berlin Heidelberd, Berlin, pp. 159-180. https://doi.org/10.1007/b89482

Ung-Medina, F., Villicaña-Méndez, M., Huirache-Acuña, R., Cortés, J.A., 2015. Experimental methodology to calculate the local relative light intensity in heterogeneous $\mathrm{TiO}_{2} / \mathrm{UV}-\mathrm{A}$ photocatalytic reactors. Chem. Eng. Res. Des. 97, 28-35. https://doi.org/10.1016/j.cherd.2015.03.012

Wang, W.Y., Ku, Y., 2006. Photocatalytic degradation of Reactive Red 22 in aqueous solution by UVLED radiation. Water Res. 40, 2249-2258. https://doi.org/10.1016/j.watres.2006.04.041 Wang, X., 2017. LED ring array light source design and uniform illumination properties analysis. Opt. Int. J. Light Electron Opt. 140, 273-281. https://doi.org/10.1016/j.ijleo.2017.04.045 